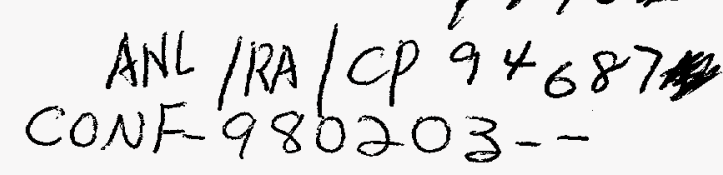

\title{
Health Physics Aspects Of Processing EBR-I Coolant
}

\author{
Lawrence L. Burke, James O. Thalgott and John W. Poston, Jr. \\ Argonne National Laboratory - West, P.O. Box 2528, Idaho Falls, ID 83403
}

MOH

$\sqrt{3}$

\section{Abstract}

The sodium-potassium reactor coolant removed from the Experimental Breeder Reactor Number One after a partial reactor core meltdown had been stored at the Idaho National Engineering and Environmental Laboratory for 40 years. The State of Idaho considered this waste the most hazardous waste stored in the state and required its processing. The reactor coolant was processed in three phases. The first phase converted the alkali metal into a liquid sodium-potassium hydroxide. The second phase converted this caustic to a liquid sodium-potassium carbonate. The third phase solidified the sodium-potassium carbonate into a form acceptable for land disposal. Health physics aspects and dose received during each phase of the processing are discussed.

\section{Introduction}

Experimental Breeder Reactor Number One (EBR-I) was a liquid metal cooled fast breeder reactor that commenced operation at the Idaho National Environmental Engineering Laboratory (INEEL) (formerly the National Reactor Testing Station) in

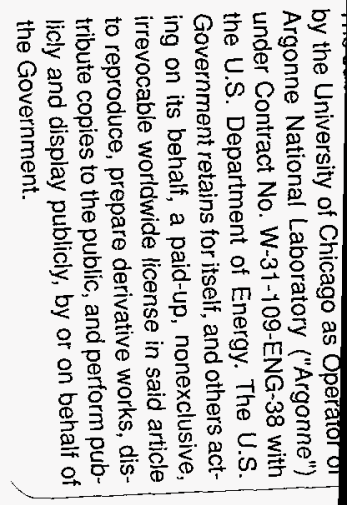
1951. The reactor coolant consisted of a eutectic mixture of sodium and potassium $(\mathrm{NaK})$. This alkali metal alloy is liquid at room temperature and burns readily when exposed to air. A partial meltdown of the EBR-I reactor core occurred on 29 November 1955 (Zinn 1956). At that time, the reactor was operating as a critical assembly with 


\section{DISCLAIMER}

This report was prepared as an account of work sponsored by an agency of the United States Government. Neither the United States Government nor any agency thereof, nor any of their employees, makes any warranty, express or implied, or assumes any legal liability or responsibility for the accuracy, completeness, or usefulness of any information, apparatus, product, or process disclosed, or represents that its use would not infringe privately owned rights. Reference herein to any specific commercial product, process, or service by trade name, trademark, manufacturer, or otherwise does not necessarily constitute or imply its endorsement, recommendation, or favoring by the United States Government or any agency thereof. The views and opinions of authors expressed herein do not necessarily state or reflect those of the United States Government or any agency thereof. 


\section{DISCLAmizR}

Portions of this doexonent moy be illegible in electronic image prodnets. Insgges are produced from the best arailabile origioal docoment. 
short reactor period and no coolant flow to study the transient temperature coefficients. After the meltdown, the coolant was drained from the reactor vessel into two 55-gallon Mine Safety Appliance (MSA) containers and two fabricated pipe sections. These containers were stored in the NaK pit located 100 yards north of building EBR-604 at the EBR-I site. The NaK contained fission products from the meltdown and was assumed to contain 10.5 grams of plutonium from foils destroyed during the meltdown (Kittel et al 1957).

On 4 April 1974, the four NaK containers were removed from the storage pit, packaged in a steel bin surrounded with dry sand and transported to the Army Reentry Vehicle Facility Site (ARVFS) located on the INEEL (Commander 1974). In 1979, a container inspection was made and a limited dose rate survey was completed. The sand around the containers was removed and replaced with vermiculite to reduce corrosion of the metal containers.

The State of Idaho and The U.S. Department of Energy issued a Consent Order requiring the processing of the EBR-I NaK to remove its hazardous characteristics. Argonne was chosen for the treatment because they had the most complete facility and years of experience in handling $\mathrm{NaK}$.

\section{Proposed NaK Treatment}

The NaK was transported in its original containers to the Argonne National Laboratory West (ANL-W) site for processing in the Sodium Component Maintenance Shop 
(SCMS). The process involved vacuum transferring the contents of the original containers into a feed tank and then, at a very controlled rate, into a water wash vessel where the $\mathrm{NaK}$ would burn in air to form sodium hydroxide $(\mathrm{NaOH})$ and potassium hydroxide $(\mathrm{KOH})$. The scrubber on the water wash vessel exhaust is used to capture the process fumes and transfer the resulting scrubber liquid to a holding tank. The caustic sodium-potassium hydroxide was to be batch processed while contained in 55-gallon drums. A sodium-potassium carbonate would be made through the addition of carbon dioxide $\left(\mathrm{CO}_{2}\right)$ in the form of dry ice. This step would lower the $\mathrm{pH}$ of the solution. Finally, the solution would be solidified through the addition of a solidification agent.

\section{Radiological Concerns and Preplanning}

From the 1974 and 1979 survey results, the expected dose rate and possible fission product inventories were estimated. The plutonium content in the NaK was estimated to be $<0.1 \%$ of the 10.5 grams available due to the high probability that the foils were contained in the molten mass of the core and the low solubility of plutonium in NaK. Table 1 compares the estimated radionuclide inventory with the actual inventory. Health physics aspects for the proposed process involved direct radiation from the $\mathrm{NaK}$, the potential for contamination spread, and the potential for airborne activity. Workers would be in close proximity to the containers to connect and disconnect $\mathrm{NaK}$ transfer lines. This operation presents a potential for personnel exposure and contamination spread during connection and disconnection. The addition of dry ice to the caustic sodium-potassium hydroxide could result in contamination spread or airborne activity. Workers would be frequently adding dry ice and monitoring conditions during the 
process. The addition of the solidification agent to the drums of solution could result in contamination spread or airborne activity.

The solution to these problems was to build overpacks that would provide shielding for the worker and containment for any loose contamination. One overpack was designed to provide an inert atmosphere for connection and disconnection of the drain lines. Fig. 1 shows this containment and the atmospheric control system. The overpack containment provided three inches of lead shielding, a containment structure with integral glove ports, and a clear viewing port on top. The other overpack was designed to provide containment during the addition of dry ice and solidification agent to the solution. Fig. 2 shows this containment. This unit attached to the 55-gallon drum with a polyvinyl chloride (PVC) sleeve for contamination control and provides two inches of lead shielding.

In order to prove the concept for the carbonation phase; several test runs were made with nonradioactive caustic sodium-potassium hydroxide solutions. During the initial tests it was determined that the containment exhaust high efficiency particulate air (HEPA) filter would plug due to excessive moisture. A condenser unit was installed in the exhaust line prior to the HEPA filter to control plugging due to moisture. This modification was not totally satisfactory as plugging was experienced when solidification agent dust was drawn into the condenser. Unfortunately, pretesting had to be curtailed due to the arrival of the NaK at the ANL-W Site. A resolution to the plugging problem was not found prior to processing the first container of $\mathrm{NaK}$. 


\section{Actual NaK Treatment}

The NaK containers were removed from the ARVFS bunker and several tests were performed including violently shaking the containers (remotely), radiography, and detailed radiation surveys. The containers were shaken to determine if potassium superoxide $\left(\mathrm{KO}_{2}\right)$ was present which might present an explosion hazard during shipment and handling at ANL-W. The presence of potassium superoxide would have been noted by an increase in container temperature after shaking. No abnormalities were noted during the test. Radiography was performed to determine the amount of material present in each container. The two 55-gallon MSA containers were full, the 60-gallon pipe section was one quarter full and the 10-gallon pipe section was full. The surveys conducted by Lockheed Martin Idaho Technology Company showed one container with removable surface contamination. This container was covered with plastic prior to placement in the shipping cask.

The containers arrived on the ANL-W site on 1 October 1995. A receipt survey of the containers was completed. The results of this survey and dose rates on the containers at various stages are provided in Table 2 . While in storage in the SCMS facility, the containers were maintained in a shielded storage area to reduce the background radiation levels in the rest of the facility. The containers were then transferred into shielded overpacks with additional shielding consisting of bags of lead shot contained within heat sealed 8 mil PVC bags placed on top the container. The PVC bags provided a surface that could be cleaned if contaminated. Dose rates on the exterior of the shielded 
overpacks were $0.3 \mathrm{mSv} / \mathrm{hr}$ ( $30 \mathrm{mR} / \mathrm{hr}$ ). Presurveys of the water wash tank, the scrubber tank, and the retention tank were completed to document their level of contamination prior to NaK solidification.

During the burning phase, it was noted that carbon dioxide scavenging from the air was occurring. This scavenging provided a method to carbonate the sodium-potassium hydroxide without using dry ice. Because the scavenging process was too inefficient to run the solution through the scrubber, a small reaction vessel was fashioned from a tank obtained from excess. Carbon dioxide gas was bubbled through the sodium-potassium hydroxide solution as it was circulated from the scrubber retention tank to the reaction vessel and back. Since personnel were not required to monitor the process, the total dose received was less than expected for carbonating with dry ice.

The final phase of the processing consisted of filling empty drums, while in a shielded overpack and contamination control containment, with carbonate solution and adding solidification agent. This mix was stirred until it set and the mixing motor stalled. The mixing blade was designed to be left in the solidified mixture. The contamination control containment was then bagged free of the drum. The solidified mixture was allowed to cure for seven days and then the drum was sealed.

\section{Conclusion}

The 125 gallons of EBR-I coolant from the core meltdown were converted to twenty-five 55-gallon drums of solid waste that was subsequently disposed of at the Radioactive 
Waste Management Complex at the INEEL. The maximal dose rate on the final product drums was $3.6 \mathrm{mSv} / \mathrm{hr}(360 \mathrm{mR} / \mathrm{hr})$. The treatment successfully removed the reactive, corrosive, and toxic characteristics of the waste. The waste form met the Resource Conservation and Recovery Act characteristics of toxicity limits for toxic metals when subjected to the Toxicity Characteristic Leaching Procedure.

The total dose for the NaK solidification project was 18.68 Person-mSv (1.868 Rem). The exposure for each phase of the project is provided in Table 3 . The miscellaneous dose was due to changing the facility HEPA filters and setup and take down of equipment. Thirty-four employees were exposed while working in radiological areas during various phases of this project. The dose distribution frequency was as follows: thirteen persons received $<0.10 \mathrm{mSv}$, twelve persons received between 0.10 and 0.99 $\mathrm{mSv}$, six persons received between 1.00 and $1.99 \mathrm{mSv}$, and three persons received between 2.00 and $2.99 \mathrm{mSv}$. Shielding with overpacks and carbonating in the small reaction vessel instead of using the original batch process saved significant dose.

Post operation surveys of the water wash tank, the scrubber tank, and the retention tank indicated significant holdup of activity in the piping of these systems as a result of the process. Hot spots on the piping were shielded to reduce ambient radiation levels in the SCMS facility. ANL-W is evaluating options to clean this piping to reduce the holdup to acceptable levels. 


\section{References}

Commander, J. C. Removal of NaK from the EBR-I storage pit. In: Decontamination and decommissioning of the EBR-I complex, Topical report no. 1. ANCR-1166/TID4500. June 1974.

Kendall, E. W.; Wang, D. K. Decontamination and decommissioning of the EBR-I complex final report. ANCR-1242. July 1975

Kittel, J. H.; Novick, M.; Buchanan, R. F. The EBR-I meltdown - physical and metallurgical changes in the core. Argonne National Laboratory. ANL-5731. November 1957.

Kittel, J. H.; Novick, M.; Buchanan, R. F.; Doe, W. B. Disassembly and metallurgical evaluation of the melted-down EBR-I core. In: Proceedings of the second United Nations international conference on peaceful uses of atomic energy. Geneva, Switzerland. September 1-13, 1958.

Zinn, W. H., A letter on EBR-I fuel meltdown, Nucleonics, 14, No. 6, 35; June 1956 
Table 1 - Estimated Versus Actual Source Term By Isotope

\begin{tabular}{lcc}
\hline Isotope & $\begin{array}{c}\text { Estimated Quantity } \\
(\mathrm{MBq})\end{array}$ & $\begin{array}{c}\text { Actual Quantity } \\
(\mathrm{MBq})\end{array}$ \\
\hline${ }^{90} \mathrm{Sr}$ & $4.0 \times 10^{4}$ & $1.4 \times 10^{5}$ \\
${ }^{90} \mathrm{Y}$ & $4.0 \times 10^{4}$ & $1.4 \times 10^{5}$ \\
${ }^{93} \mathrm{Zr}$ & $1.3 \times 10^{1}$ & Not Detected \\
${ }^{99} \mathrm{Tc}$ & $5.1 \times 10^{1}$ & $2.3 \times 10^{1}$ \\
${ }^{106} \mathrm{Ru}$ & $7.2 \times 10^{-7}$ & Not Detected \\
${ }^{106} \mathrm{Rh}$ & $7.2 \times 10^{-7}$ & Not Detected \\
${ }^{113 \mathrm{~m}} \mathrm{Cd}$ & Not Expected & $1.0 \times 10^{2}$ \\
${ }^{121 \mathrm{~m}} \mathrm{Sn}$ & $1.7 \times 10^{1}$ & Not Detected \\
${ }^{125} \mathrm{Sb}$ & $2.5 \times 10^{0}$ & Not Detected \\
${ }^{125 \mathrm{~m}} \mathrm{Te}$ & $7.0 \times 10^{-2}$ & Not Detected \\
${ }^{135} \mathrm{Cs}$ & $6.0 \times 10^{0}$ & Not Detected \\
${ }^{137} \mathrm{Cs}$ & $3.1 \times 10^{5}$ & $1.5 \times 10^{5}$ \\
${ }^{137 \mathrm{~m}} \mathrm{Ba}$ & $2.9 \times 10^{5}$ & $1.4 \times 10^{5}$ \\
${ }^{147} \mathrm{Pm}$ & $1.3 \times 10^{1}$ & Not Detected \\
${ }^{151} \mathrm{Sm}$ & $1.8 \times 10^{3}$ & $4.6 \times 10^{3}$ \\
${ }^{152} \mathrm{Eu}$ & Not Expected & $1.2 \times 10^{1}$ \\
${ }^{154} \mathrm{Eu}$ & Not Expected & $1.4 \times 10^{3}$ \\
${ }^{239} \mathrm{Pu}$ & $2.4 \times 10^{1}$ & $1.1 \times 10^{1}$ \\
${ }^{240} \mathrm{Pu}$ & $4.4 \times 10^{0}$ & Not Detected \\
${ }^{241} \mathrm{Pu}$ & $2.1 \times 10^{1}$ & Not Detected \\
${ }^{242} \mathrm{Pu}$ & $1.8 \times 10^{-4}$ & Not Detected \\
${ }^{241} \mathrm{Am}$ & $3.4 \times 10^{0}$ & Not Detected \\
\hline & $6.9 \times 10^{5}$ & $5.9 \times 10^{5}$ \\
\hline
\end{tabular}

${ }^{a}$ H. K. Peterson, "Best Estimate of the Radionuclides Contained in the EBR-I NaK," Lockheed Martin Idaho Technologies Company, Engineering Design File, RE-005-93, May 5, 1993.

${ }^{b}$ U.S. Department of Energy, Idaho Operations Office, Radioactive Waste Management Information System, Computer Equivalent - US DOE ID F 5820.2, Stored, Disposed, or Processed Solid Radioactive Waste Form Containerized Waste Summary for Shipment No. AW-96-024 and AW-96-025. 
Table 2 - NaK Container Dose Rates

\begin{tabular}{lcccc}
\hline \multirow{2}{*}{$\begin{array}{c}\text { Container Status } \\
\text { Reading Position }\end{array}$} & \multicolumn{5}{c}{ Container Dose Rate (mSv) } \\
\cline { 2 - 5 } & MSA & MSA & 60 Gallon & 10 Gallon \\
No. 1 & No. 2 & Container & Container \\
\hline Loaded & & & & \\
Top & 8.0 & 20 & 2.0 & 1.5 \\
Side & 38 & 45 & 10 & 5.0 \\
$\quad$ Bottom & 40 & 45 & 10 & 10 \\
Emptied & & & & \\
$\quad$ Top & 0.12 & NR & 0.13 & NR \\
Side & 0.25 & 0.50 & 0.50 & NR \\
$\quad$ Bottom & 2.0 & 0.60 & 1.0 & NR \\
Rinsed & & & & \\
$\quad$ Maximum & 0.040 & 0.30 & 0.040 & 0.11 \\
\hline
\end{tabular}

NR - No reading taken at this location. 
Table 3 - Total Dose By Activity

\begin{tabular}{lc}
\hline \multicolumn{1}{c}{ Activity } & Dose (Person-mSv) \\
\hline Transfer NaK Containers to Overpacks & 3.00 \\
Transfer Nak to Feed Containers and then Burn & 3.85 \\
Neutralize Sodium-potassium Hydroxide & 2.60 \\
Solidify Sodium-potassium Carbonate & 3.10 \\
React Residual NaK in Containers & 0.50 \\
Transfer Waste Drums to RWMC & 1.93 \\
Miscellaneous & 3.70 \\
\hline & Total \\
\hline
\end{tabular}




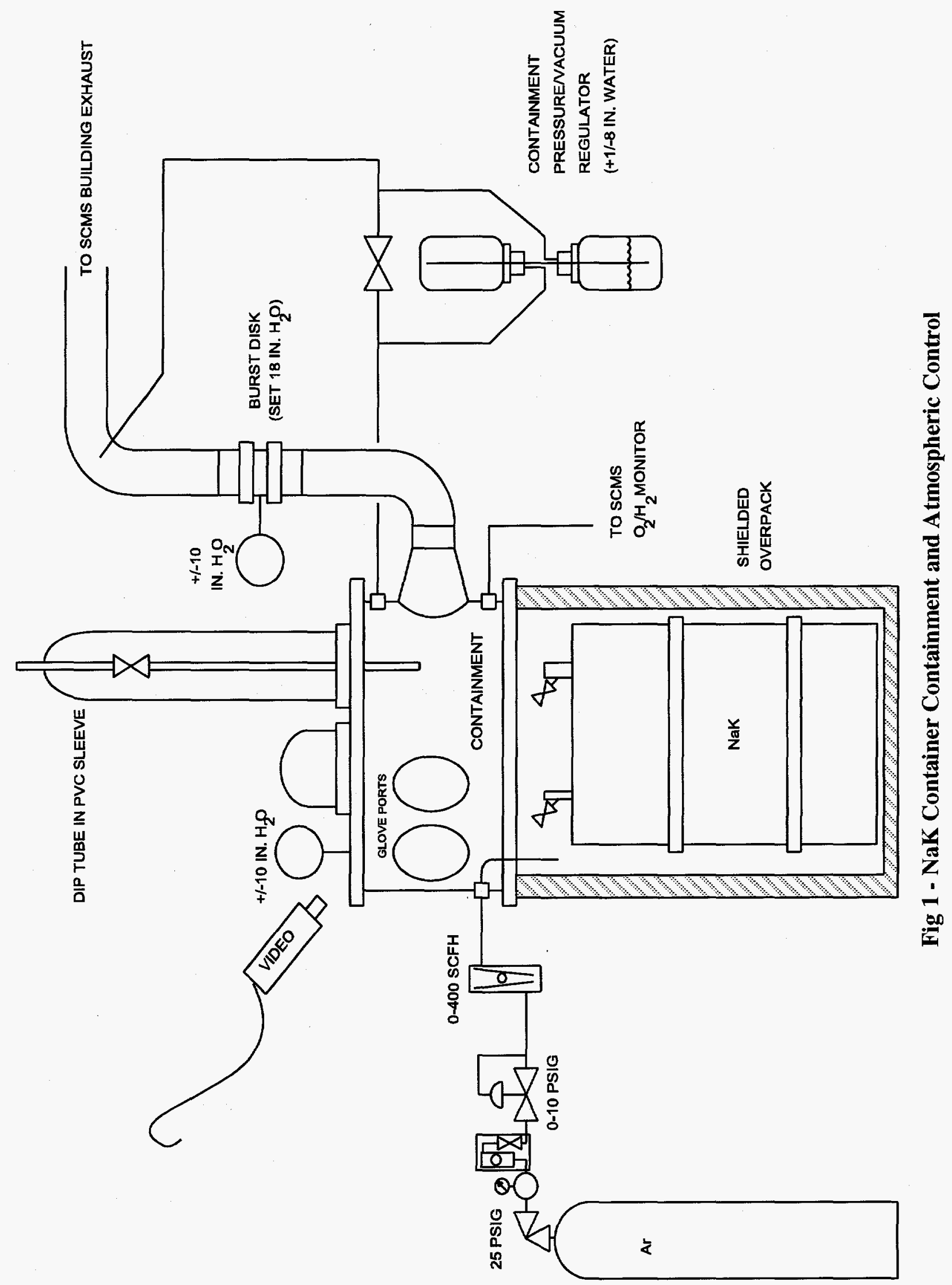




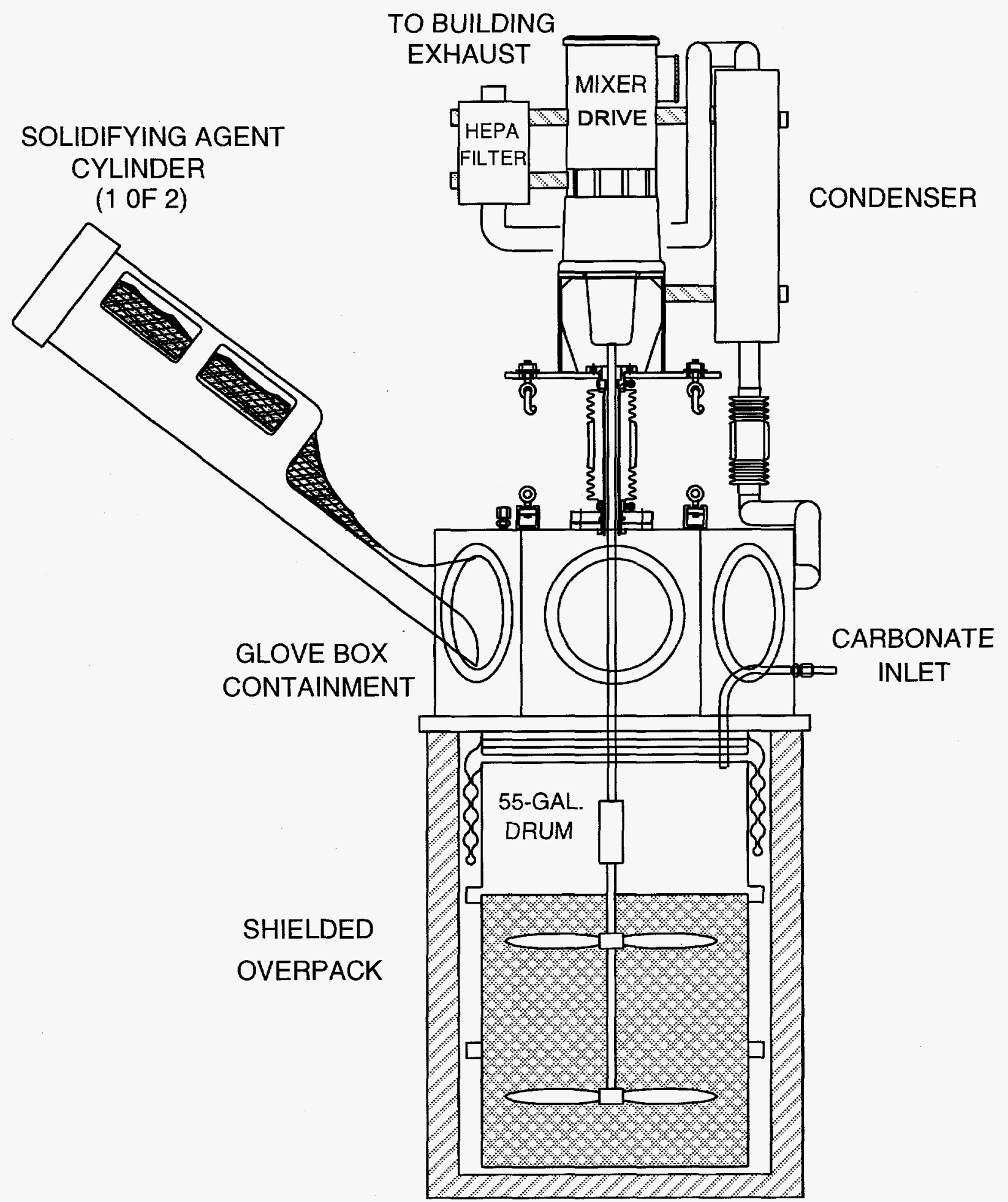

Fig. 2 - Liquid Carbonate Solidification Containment 